\title{
Si doped GaP layers grown on Si wafers by low temperature PE-ALD
}

A. S. Gudovskikh, A. V. Uvarov, I. A. Morozov, A. I. Baranov, D. A. Kudryashov, E. V. Nikitina, A. A. Bukatin, K. S. Zelentsov, I. S. Mukhin, A. Levtchenko, S. Le Gall, and J.-P. Kleider

Citation: Journal of Renewable and Sustainable Energy 10, 021001 (2018); doi: 10.1063/1.5000256

View online: https://doi.org/10.1063/1.5000256

View Table of Contents: http://aip.scitation.org/toc/rse/10/2

Published by the American Institute of Physics 


\title{
Si doped GaP layers grown on Si wafers by low temperature PE-ALD
}

\author{
A. S. Gudovskikh, ${ }^{1,2}$ A. V. Uvarov, ${ }^{1}$ I. A. Morozov, ${ }^{1}$ A. I. Baranov, ${ }^{1}$ \\ D. A. Kudryashov, ${ }^{1}$ E. V. Nikitina, ${ }^{1}$ A. A. Bukatin, ${ }^{1}$ K. S. Zelentsov, ${ }^{1}$ \\ I. S. Mukhin, ${ }^{1}$ A. Levtchenko, ${ }^{3}$ S. Le Gall, ${ }^{3}$ and J.-P. Kleider ${ }^{3}$ \\ ${ }^{1}$ St.Petersburg National Research Academic University RAS, 194021 St. Petersburg, Russia \\ ${ }^{2}$ Saint-Petersburg Electrotechnical University “LETI," 197376 Saint-Petersburg, Russia \\ ${ }^{3}$ GeePs, Group of Electrical Engineering - Paris, UMR 8507 CNRS, Centrale Supélec, \\ Univ. Paris-Sud, Université Paris-Saclay Sorbonne Universités, UPMC Univ Paris 06, \\ 91192 Gif-sur-Yvette Cedex, France
}

(Received 14 August 2017; accepted 4 January 2018; published online 16 March 2018)

\begin{abstract}
Low-temperature plasma enhanced atomic layer deposition (PE-ALD) was successfully used to grow silicon ( $\mathrm{Si}$ ) doped amorphous and microcrystalline gallium phosphide $(\mathrm{GaP})$ layers onto p-type $\mathrm{Si}$ wafers for the fabrication of $\mathrm{n}-\mathrm{GaP} / \mathrm{p}-\mathrm{Si}$ heterojunction solar cells. PE-ALD was realized at $380^{\circ} \mathrm{C}$ with continuous $\mathrm{H}_{2}$ plasma discharge and the alternate use of phosphine and trimethylgallium as sources of $\mathrm{P}$ and $\mathrm{Ga}$ atoms, respectively. The layers were doped with silicon thanks to silane $\left(\mathrm{SiH}_{4}\right)$ diluted in $\mathrm{H}_{2}$ that was introduced as a separated step. High $\mathrm{SiH}_{4}$ dilution in $\mathrm{H}_{2}$ $(0.1 \%)$ allows us to deposit stoichiometric GaP layers. Hall measurements performed on the GaP:Si/p-Si structures reveal the presence of an n-type layer with a sheet electron density of $6-10 \times 10^{13} \mathrm{~cm}^{-2}$ and an electron mobility of $13-25 \mathrm{~cm}^{2} \mathrm{~V}^{-1} \mathrm{~s}^{-1}$ at $300 \mathrm{~K}$. This is associated with the formation of a strong inversion layer in the p-Si substrate due to strong band bending at the $\mathrm{GaP} / \mathrm{Si}$ interface. $\mathrm{GaP}: \mathrm{Si} / \mathrm{p}-\mathrm{Si}$ heterostructures exhibit a clear photovoltaic effect, with the performance being currently limited by the poor quality of the p-Si wafers and reflection losses at the GaP surface. This opens interesting perspectives for Si doped GaP deposited by PE-ALD for the fabrication of p-Si based heterojunction solar cells. Published by AIP Publishing. https://doi.org/10.1063/1.5000256
\end{abstract}

\section{INTRODUCTION}

Silicon based solar cells are by far dominating the PV market due to the availability and relatively low price of $\mathrm{Si}$ substrates. One of the most efficient ways to increase the $\mathrm{Si}$ solar cell performance is to use heterojunction designs. Thus, heterojunctions between hydrogenated amorphous silicon (a-Si:H) and crystalline silicon (c-Si) have reached conversion efficiencies of $24.7 \%$ for n-type $\mathrm{Si}$ wafers with conventional architecture and $26.3 \%$ when combined with interdigitated back contacts. ${ }^{1}$ Thin layers of a-Si:H with a gap of $1.65-1.75 \mathrm{eV}$ provide an excellent passivation of the c-Si surface with relatively low light absorption in a-Si:H. An increase in the Si heterojunction solar cell efficiency could be achieved by further reducing the absorption in the emitter layer using a material with a higher bandgap. On the other hand, a$\mathrm{Si}: \mathrm{H} / \mathrm{c}-\mathrm{Si}$ heterojunctions are not so successful for p-type Si wafers, which are still of interest for low orbit space applications due to better radiation hardness. ${ }^{2}$ Gallium phosphide (GaP) has an indirect bandgap of $2.26 \mathrm{eV}$ that is suitable for low absorption losses. Taking into account a very small difference in the lattice constant between $\mathrm{GaP}$ and $\mathrm{Si}$, the $\mathrm{GaP} / \mathrm{Si}$ heterojunction could be a good candidate for photovoltaic applications. The GaP/Si interface has a relatively low conduction band energy offset $\left(\Delta \mathrm{E}_{\mathrm{C}}=0.2-0.35 \mathrm{eV}\right)$ and a significant valence band offset $\left(\Delta \mathrm{E}_{\mathrm{V}}=0.8-0.95 \mathrm{eV}\right),{ }^{3,4}$ making $\mathrm{n}-\mathrm{GaP} / \mathrm{p}$-Si heterojunctions based on $\mathrm{p}$-type $\mathrm{Si}$ wafers preferable for solar cell applications. The transport across the junction of holes that are photogenerated in $\mathrm{p}$-Si is limited by the large valence band offset at the $\mathrm{GaP} / \mathrm{Si}$ interface, which limits 
recombination losses. On the other hand, electrons can easily overpass the spike formed by small $\Delta \mathrm{E}_{\mathrm{C}}{ }^{5}$ However, high temperatures which are commonly used for GaP growth using conventional techniques such as molecular beam epitaxy (MBE) and metal organic vapor-phase epitaxy (MOVPE) lead to lifetime degradation in the Si wafers. ${ }^{6,7}$ Recently, we have demonstrated that growth of GaP by plasma-enhanced atomic layer deposition (PE-ALD) at relatively low temperature (below $400^{\circ} \mathrm{C}$ ) does not affect $\mathrm{Si}$ substrate quality. ${ }^{7}$ However, an n-type GaP layer is required for the fabrication of $\mathrm{n}-\mathrm{GaP} / \mathrm{p}-\mathrm{Si}$ heterojunctions. Silicon is commonly used as an impurity in $\mathrm{GaP}$ for donor-type doping. ${ }^{8,9}$ Here, we report about the Si doping facility of $\mathrm{GaP}$ using PE-ALD for the fabrication of $\mathrm{GaP} / \mathrm{Si}$ solar cells based on p-type $\mathrm{Si}$ wafers.

\section{EXPERIMENTAL DETAILS}

The GaP layers were grown by PE-ALD at $380^{\circ} \mathrm{C}$ using an Oxford Plasmalab 100 PECVD $(13.56 \mathrm{MHz})$ setup. Fused silica and Si substrates of (100) orientation with $4^{\circ}$ cut-off towards (110) were used. We used boron doped p-type and phosphorous doped n-type Si wafers with dopant concentrations of $10^{16} \mathrm{~cm}^{-3}$ and $10^{15} \mathrm{~cm}^{-3}$, respectively. To realize the PE-ALD process, phosphine $\left(\mathrm{PH}_{3}\right)$ and trimethylgallium (TMG) flows were alternatively changed with continuous plasma discharge due to constant hydrogen $\left(\mathrm{H}_{2}\right)$ flow during the growth and purge steps. TMG was carried by hydrogen. The gas mixture pressure and total gas flow were fixed at $350 \mathrm{mTorr}$ and $100 \mathrm{sccm}$, respectively. Amorphous and microcrystalline GaP films were grown by varying $\mathrm{RF}$ glow discharge power. Amorphous GaP (a-GaP) layers were deposited at a constant RF power of $20 \mathrm{~W}$, while for the growth of microcrystalline ( $\mu \mathrm{c}-\mathrm{GaP})$ films, a pulsed increase in RF power to $100 \mathrm{~W}$ was used during $\mathrm{Ga}$ and $\mathrm{P}$ deposition steps. In both cases, the conditions of one monolayer growth by cycle (growth rate of about $0.25 \mathrm{~nm}$ per cycle) were reached by choosing appropriate TMG and $\mathrm{PH}_{3}$ dilution in hydrogen and deposition time, which are presented in Table I. An additional step of $\mathrm{H}_{2}$ plasma annealing at a $\mathrm{RF}$ power of $100 \mathrm{~W}$ for $2 \mathrm{~s}$ was introduced to etch excess phosphorous deposited at the chamber wall. Each Ga and P deposition step was separated by at least $7 \mathrm{~s}$ long purge step with constant $\mathrm{H}_{2}$ flow and minimal $(20 \mathrm{~W}) \mathrm{RF}$ power required to maintain plasma discharge. According to TEM studies, a-GaP layers have a homogeneous amorphous structure with a small amount of $2-3 \mathrm{~nm}$ size nanocrystalline inclusions, while for $\mu \mathrm{c}-\mathrm{GaP}$ layers, electron diffraction exhibits sharp rings corresponding to the microcrystalline structure. The grain size of 5-10 nm for $\mu \mathrm{c}-\mathrm{GaP}$ was estimated from HRTEM measurements.

For Si doping of GaP in the case of PE-ALD technology, silane $\left(\mathrm{SiH}_{4}\right)$ seems to be the more appropriate source of silicon because it is easy to control and no additional negative effect of hydrogen or $\mathrm{SiH}_{\mathrm{x}}$ radicals is expected. Silane diluted in hydrogen $\left(0.1\right.$ and $10 \% \mathrm{SiH}_{4} \mathrm{H}_{2}$ ) was added as a separate step after $\mathrm{PH}_{3}$ deposition for Si doping. This doping step was carried out for a minimal time $(2 \mathrm{~s})$ and at minimal RF power $(20 \mathrm{~W})$, which are possible for stable reproduction. All GaP:Si deposition processes consisted of 200 cycles, which correspond to a thickness of about $50 \mathrm{~nm}$.

Raman spectroscopy was used to study the structural properties of the films. Raman spectra were measured using a Horiba Jobin Yvon LABRAM HR 800 spectrometer with a laser excitation at $532 \mathrm{~nm}$. Energy-dispersive X-ray spectroscopy (EDX) and Pulsed RF Glow Discharge Optical Emission Spectrometry (GDOES) ${ }^{10}$ were used for composition analysis of the films. The scanning electron microscope Quantum Inspect FEI supplied with an EDX analyzer was used with an

TABLE I. TMG and $\mathrm{PH}_{3}$ dilution in hydrogen and deposition time for a-GaP and $\mu \mathrm{c}-\mathrm{GaP}$.

\begin{tabular}{lcc}
\hline \hline & a-GaP & $\mu$ c-GaP \\
\hline TMG step time, $\mathrm{s}$ & 5 & 4 \\
TMG: $\mathrm{H}_{2}$ dilution, $\%$ & $1.4 \pm 0.2$ & $1.4 \pm 0.2$ \\
$\mathrm{PH}_{3}$ step time, $\mathrm{s}$ & 3 & 2 \\
$\mathrm{PH}_{3}: \mathrm{H}_{2}$ dilution, $\%$ & $50 \pm 2$ & $30 \pm 2$ \\
\hline \hline
\end{tabular}


acceleration voltage of $15-25 \mathrm{kV}$ and a probe area of $10 \times 10 \mu \mathrm{m}^{2}$. The GDOES study was performed for a probe area of approximately $1 \mathrm{~cm}^{2}$ using a HORIBA Jobin Yvon GD-Profiler.

Electronic properties were studied by I-V and Hall Effect measurements using a Keithley 2400 source-meter and an Ecopia HMS-3000, respectively. First, the electrical measurements were performed for $\mathrm{GaP}$ films deposited on p- and n-type Si substrates using simple Indium (In) dot contacts. Then, Ti/Ag non-alloyed ohmic contacts were formed on the top of $\mathrm{GaP}: \mathrm{Si} / \mathrm{p}-\mathrm{Si}$ structures using lithography for advanced electrical characterization. The design of the contacts, which is shown in Fig. 1, allows us to estimate the contact resistivity using transmission line measurement (TLM) tests, to provide Hall measurements, and to study the photoelectrical properties of $\mathrm{GaP}: \mathrm{Si} / \mathrm{p}-\mathrm{Si}$ heterostructures. Ti/Ag contacts exhibit ohmic behavior with the contact resistivity of $0.17 \Omega \mathrm{cm}^{2}$ obtained without any thermal treatment. For photoelectrical measurements, the bottom contact to p-Si was formed by PECVD of p-type a-Si:H and Ag evaporation.

\section{RESULTS AND DISCUSSION}

Raman spectra of the GaP:Si films deposited with different silane concentrations are presented in Fig. 2. When $0.1 \% \mathrm{SiH}_{4}$ dilution in $\mathrm{H}_{2}$ is used, the Raman spectra exhibit either a broad feature at $360 \mathrm{~cm}^{-1}$ corresponding to amorphous $\mathrm{GaP}^{11}$ in the case of a-GaP deposition conditions or two peaks at appropriate TO and LO positions of $\mathrm{GaP}^{12}\left(365\right.$ and $\left.402 \mathrm{~cm}^{-1}\right)$ in the case of $\mu \mathrm{c}-\mathrm{GaP}$ growth. Thus, Raman spectra confirm no structural changes due to Si doping for $0.1 \% \mathrm{SiH}_{4}$ concentration. However, when $10 \% \mathrm{SiH}_{4}$ dilution is used, a drastic change occurs in the Raman spectra, with the appearance of a broad feature at $460 \mathrm{~cm}^{-1}$. This probably corresponds to a shifted peak position of a-Si:H $\left(480 \mathrm{~cm}^{-1}\right)$ rather than a-GaP, indicating a significant change in the layer composition. In this paper, only the GaP:Si films obtained with $0.1 \% \mathrm{SiH}_{4}$ dilution will be further considered.

From EDX measurements, almost stoichiometric composition of GaP layers was found (50\% of $\mathrm{Ga}$ and $50 \%$ of $\mathrm{P}$ with an error of $\pm 5 \%$ ). However, no indication of $\mathrm{Si}$ could be detected by EDX due to the detection limit for thin samples (50 nm thickness). The stoichiometric composition was confirmed from GDOES measurements, where traces of silicon have also been observed. However, the precise estimation of the silicon content is also difficult using this technique due to the very low layer thickness. By comparing the data obtained on our PEALD sample with data obtained on an MBE sample with a known Si doping concentration $\left(4 \times 10^{18} \mathrm{~cm}^{-3}\right)$, we estimate that the concentration of $\mathrm{Si}$ in the PE-ALD sample is of the order of $10^{19} \mathrm{~cm}^{-3}$.

The dark I-V curves for the GaP:Si/p-Si and GaP:Si/n-Si heterostructures with top and bottom In contacts are plotted in Fig. 3 on a linear scale. The I-V curves for a-GaP:Si and $\mu \mathrm{c}-\mathrm{GaP}: \mathrm{Si}$

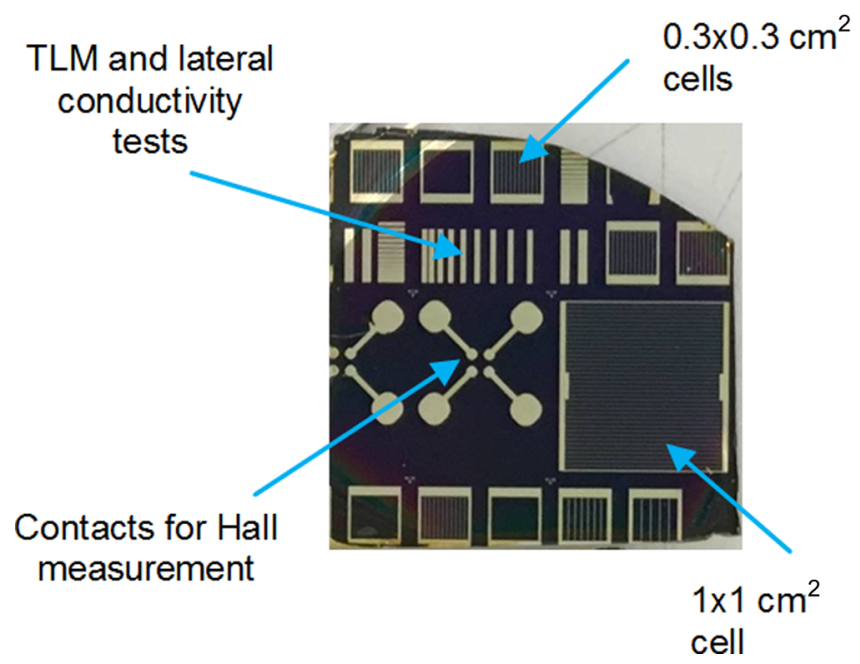

FIG. 1. Photography of Ti/Ag contacts formed on the top of GaP:Si/p-Si heterostructures. 


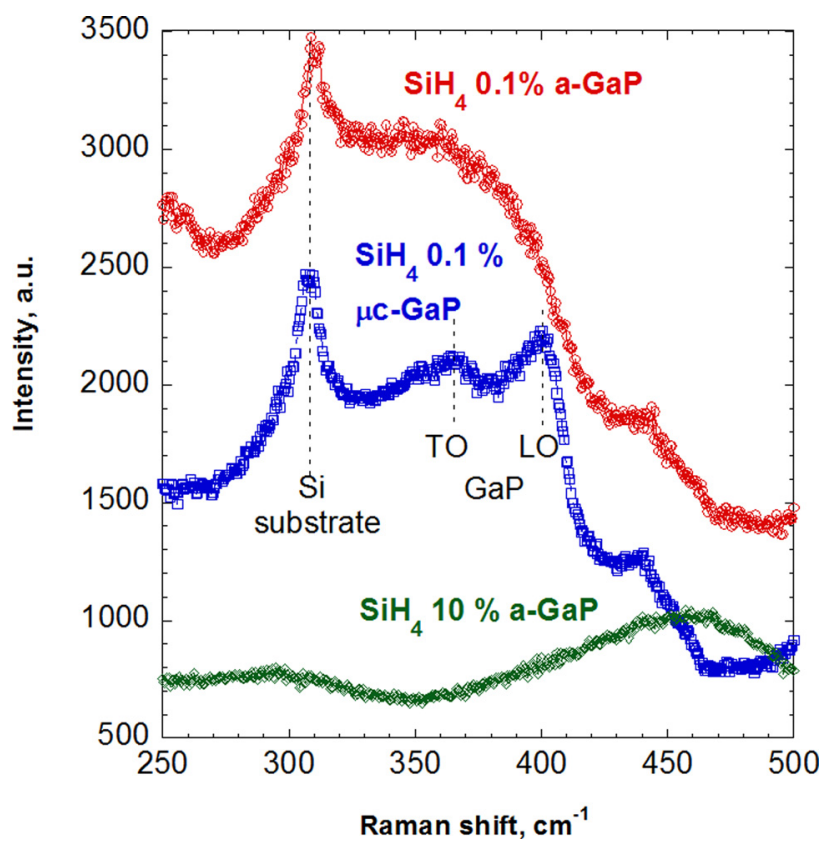

FIG. 2. Raman spectra of the GaP:Si films deposited with silane concentrations of $0.1 \%$ and $10 \%$.

layers deposited on p-Si substrates exhibit rectifying behavior [Fig. 3(a)], while In forms an ohmic contact to $\mathrm{GaP}: \mathrm{Si}$ and $\mathrm{p}-\mathrm{Si}$. For the structures deposited on $\mathrm{n}-\mathrm{Si}$, the I-V curves have nonrectifying behavior [Fig. 3(b)]. The curves are not strictly linear because of the nonlinear behavior of the bottom In/n-Si contact.

Since a rectifying behavior of I-V curves for the GaP:Si/p-Si heterojunction was observed, the presence of a barrier and a space region in $\mathrm{Si}$ is suspected. Therefore, when electrical measurements between $\mathrm{Ti} / \mathrm{Ag}$ planar top electrodes are performed, no current passes through the p-Si substrate due to reverse connection of one of the n-p junctions (Fig. 4).

Hall measurements were carried out between four Ti/Ag planar top electrodes deposited on top of GaP:Si/p-Si structures (Fig. 1). They demonstrate the presence of an n-type layer. The obtained sheet electron density $\left(\mathrm{N}_{\mathrm{s}}\right)$, mobility $\left(\mu_{\mathrm{n}}\right)$, and electron concentration $(\mathrm{n})$ assuming a $50 \mathrm{~nm}$ thickness of this n-type layer at 300 and $77 \mathrm{~K}$ are given in Table II. The general trend of
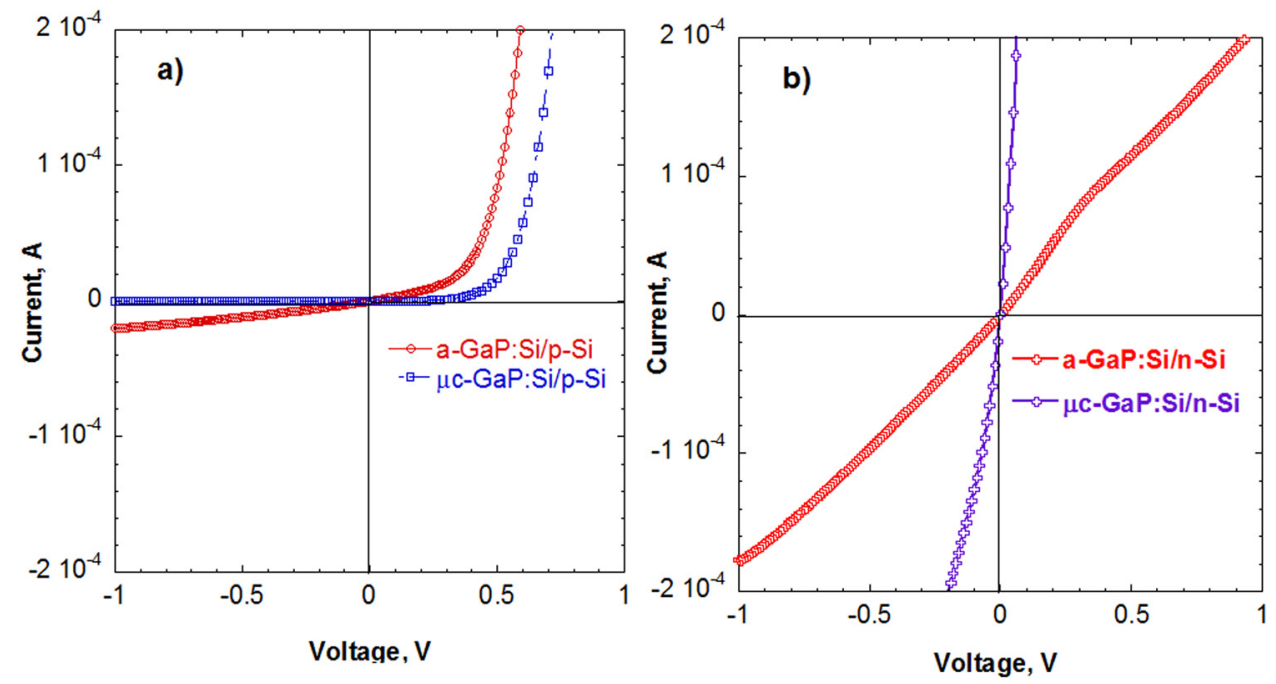

FIG. 3. The dark I-V curve for the GaP:Si/p-Si (a) and GaP:Si/n-Si (b) heterostructures. 


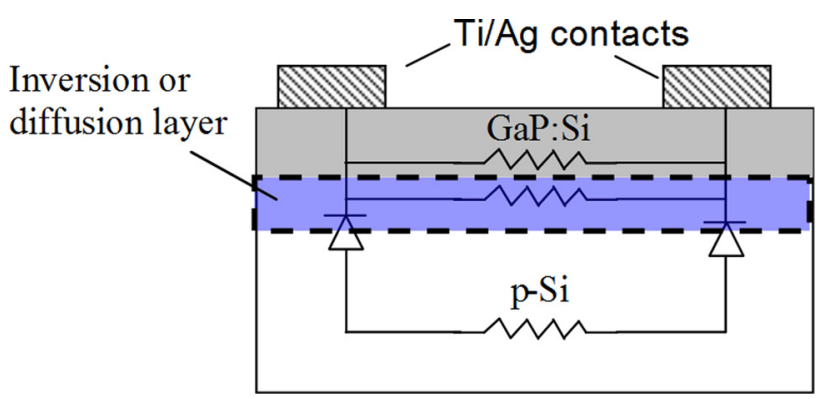

FIG. 4. Schematic presentation of the planar electrical measurements on the GaP:Si/p-Si heterojunction structure.

TABLE II. Electron sheet density $\left(\mathrm{N}_{\mathrm{s}}\right)$, mobility $\left(\mu_{\mathrm{n}}\right)$, and related electron concentration $(\mathrm{n})$ (assuming $50 \mathrm{~nm}$ thickness) obtained from Hall measurements for a-GaP:Si/p-Si and $\mu \mathrm{c}-\mathrm{GaP}: \mathrm{Si} / \mathrm{p}-\mathrm{Si}$ heterostructures at 300 and $77 \mathrm{~K}$.

\begin{tabular}{lcccc}
\hline \hline & & $\mathrm{N}_{\mathrm{s}}, 10^{13} \mathrm{~cm}^{-2}$ & $\mu_{\mathrm{n}}, \mathrm{cm}^{2} \mathrm{~V}^{-1} \mathrm{~s}^{-1}$ & $\mathrm{n}, 10^{19} \mathrm{~cm}^{-3}$ \\
\hline a-GaP:Si/p-Si & $\mathrm{T}=300 \mathrm{~K}$ & $8.7 \pm 1.2$ & $21.5 \pm 3.5$ & $2.0 \pm 0.3$ \\
& $\mathrm{~T}=77 \mathrm{~K}$ & $4.0 \pm 0.4$ & $12.0 \pm 2.0$ & $0.82 \pm 0.09$ \\
& $\mathrm{~T}$ c-GaP:Si/p-Si & $7.1 \pm 1.2$ & $16.0 \pm 3.0$ & $1.5 \pm 0.3$ \\
& $\mathrm{~T}=300 \mathrm{~K}$ & $4.5 \pm 0.4$ & $5.0 \pm 1.0$ & $0.88 \pm 0.09$ \\
\hline \hline
\end{tabular}

slight electron concentration decrease along with a slight drop of mobility is observed for low temperature $(77 \mathrm{~K})$ Hall measurements. The drop of $\mu_{\mathrm{n}}$ with the temperature decrease suggests that scattering at ionized impurities is a dominating mechanism for electrons in the n-type layer.

There are three possible reasons for the formation of an n-type layer at the GaP/Si surface (Fig. 4): (i) strong n-type doping of $\mathrm{GaP}$; (ii) formation of a strong inversion electron layer in $\mathrm{p}-\mathrm{Si}$ due to strong band bending at the $\mathrm{GaP} / \mathrm{Si}$ interface (see the band diagram in Fig. 5) similar to the a-Si:H/c-Si case; ${ }^{13}$ (iii) formation of an n-type layer in the $\mathrm{Si}$ substrate due to $\mathrm{P}$ diffusion during $\mathrm{GaP}$ growth. The last possible reason can be excluded thanks to planar conductance measurements. Indeed, the top GaP layer was removed using wet selective etchant $\left(\mathrm{HNO}_{3}: \mathrm{HCl}_{2} \mathrm{H}_{2} \mathrm{SO}_{4}: \mathrm{H}_{2} \mathrm{O}\right)$ without etching the Si surface. The planar conductance dropped drastically in this case (Fig. 6).

Regarding the other two possible reasons, the band diagram calculated using AFORS-HET software $^{14}$ (Fig. 5) demonstrates that the formation of a strong inversion layer can only be possible if the Fermi level of GaP is extremely close to the conduction band. As a consequence,

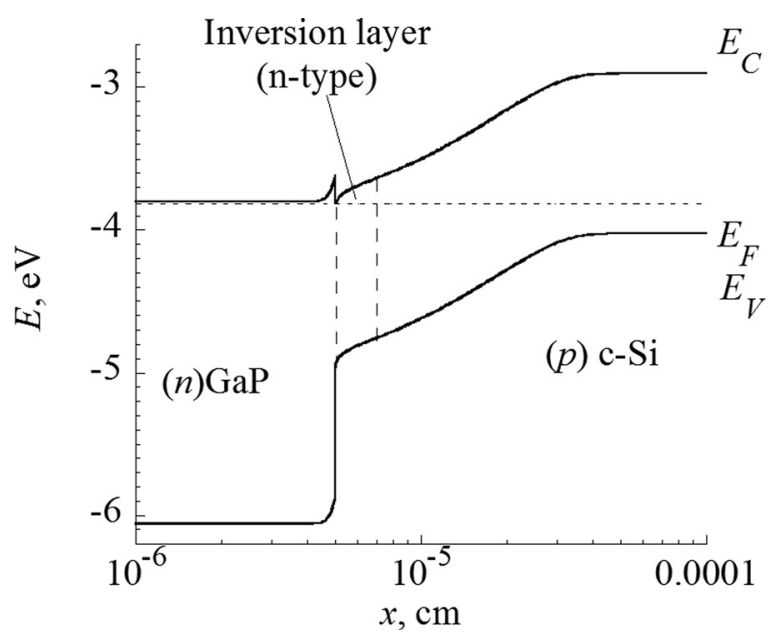

FIG. 5. Calculated band diagram of the $\mathrm{n}-\mathrm{GaP} / \mathrm{p}-\mathrm{Si}$ heterojunction where an inversion layer in $\mathrm{p}-\mathrm{Si}$ could be formed. 


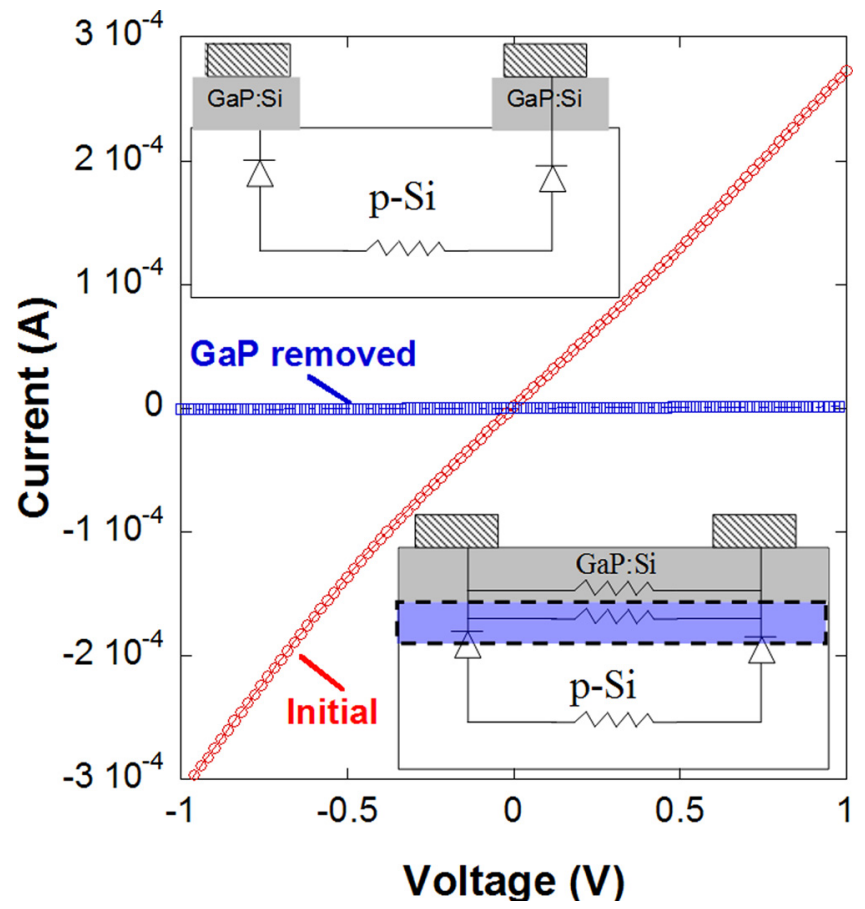

FIG. 6. I-V curves measured between two planar electrodes before and after selective GaP etching.

both possible reasons imply that the GaP layer is n-type doped. Therefore, we can conclude that n-type Si doped GaP films were successfully obtained by PE-ALD using $\mathrm{SiH}_{4}$ as a silicon source.

The measured electron mobility values are close to that for bulk or epitaxial GaP $\left(20-50 \mathrm{~cm}^{2} \mathrm{~V}^{-1} \mathrm{~s}^{-1}\right)$ for the doping level $>10^{19} \mathrm{~cm}^{-3} .{ }^{15}$ However, taking into account the amorphous or microcrystalline structure of our PE-ALD GaP layers, the measured mobility is likely to be related to a strong inversion layer in silicon. The electron mobility in $\mathrm{Si}$ inversion layers is significantly lower compared to that of bulk $\mathrm{Si}$ due to interface scattering. ${ }^{16}$ For $_{\mathrm{SiO}_{2} /}$ $\mathrm{Si}$ with low interface state density, the mobility is in the range of $100-800 \mathrm{~cm}^{2} \mathrm{~V}^{-1} \mathrm{~s}^{-1}$ for a sheet electron density of $10^{13}-10^{11} \mathrm{~cm}^{-2} \cdot{ }^{17,18}$ However, the maximum values reported for $\mathrm{N}_{\mathrm{s}}$ in electron inversion layers formed in Si based MOS structures reach $10^{13} \mathrm{~cm}^{-2}$ which is almost one order of magnitude lower compared to the measured values for $\mathrm{GaP} / \mathrm{Si}$ structures. The higher value of $\mathrm{N}_{\mathrm{s}}$ and interface defect density for a-GaP:Si/p-Si and $\mu \mathrm{c}-\mathrm{GaP}: \mathrm{Si} / \mathrm{p}-\mathrm{Si}$ structures thus could lead to $\mu_{\mathrm{n}}$ reduction in the $\mathrm{Si}$ inversion layer at the GaP interface.

The planar conductance of the n-type layer, presented in Fig. 7, has a weak temperature dependence, which according to Hall measurements is rather related to mobility changes with temperature. This planar conductance of $\mathrm{GaP}: \mathrm{Si} / \mathrm{p}-\mathrm{Si}$ structures is few orders of magnitude higher compared to that of a-GaP and $\mu \mathrm{c}-\mathrm{GaP}$ layers deposited on fused silica (Fig. 7), indicating a strong difference in transport mechanisms.

The appearance of an inversion layer at the $\mathrm{GaP} / \mathrm{p}-\mathrm{Si}$ interface means strong band bending in $\mathrm{p}-\mathrm{Si}$, which is obviously required for efficient solar cells. The I-V curves under illumination for GaP:Si/p-Si heterojunctions with a Ti/Ag grid demonstrate the photovoltaic behavior [Fig. 8(a)] with an open circuit voltage (Voc) of $0.45-0.50 \mathrm{~V}$, confirming a significant band bending in p-Si. The shape of I-V curves at $\mathrm{V}>0.4 \mathrm{~V}$ is affected by the $\mathrm{p}-\mathrm{Si} /(\mathrm{p}) \mathrm{a}-\mathrm{Si}: \mathrm{H}$ bottom contact. It could be related to contamination of the $\mathrm{p}-\mathrm{Si}$ back surface during GaP deposition. When (p)a-Si:H was mechanically removed and replaced by In, an improvement of I-V curve behavior occurs [Fig. 8(b)]. The observed S-shape of I-V curves, which is also called the "rollover effect," was previously observed and explained by transport limitation due to the influence of the potential barriers for the majority carriers or rectifying back contact. ${ }^{19-23}$ Further optimization of the back contact 


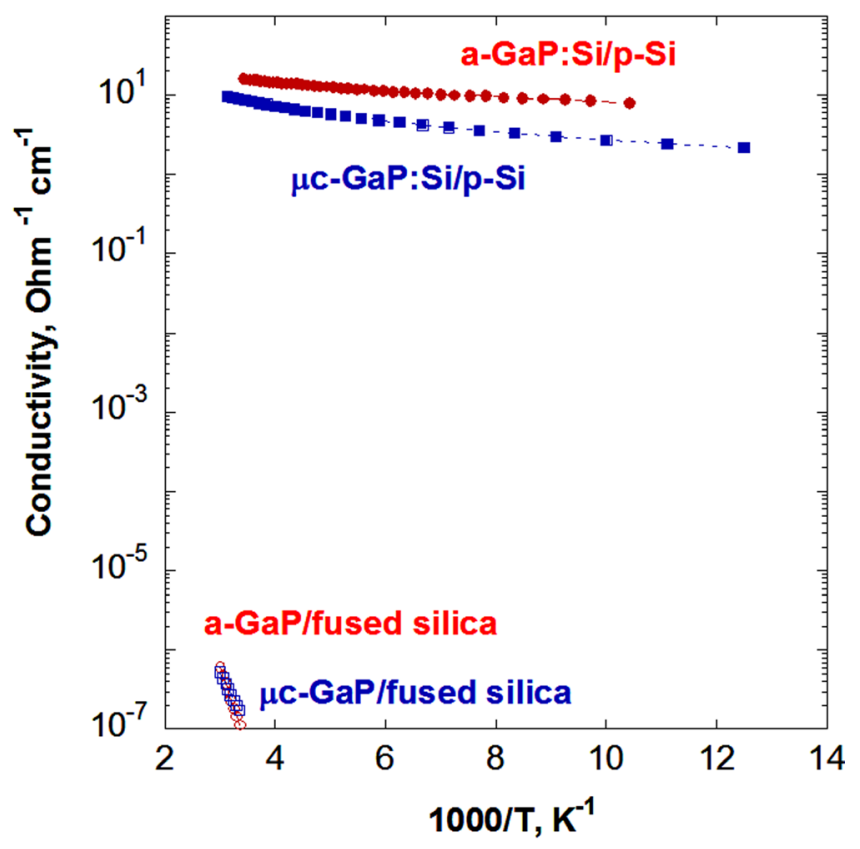

FIG. 7. Temperature dependence of the planar conductance for a-GaP and $\mu \mathrm{c}-\mathrm{GaP}$ layers deposited on fused silica and for $\mathrm{GaP}: \mathrm{Si} / \mathrm{p}-\mathrm{Si}$ structures assuming a thickness of $50 \mathrm{~nm}$.

was done using an Al BSF (Back Surface Field), which was fabricated by $\mathrm{Al}$ evaporation and annealing at $750^{\circ} \mathrm{C}$ prior to $\mathrm{GaP}$ deposition. The I-V curve does not exhibit the rollover effect with the Al BSF [Fig. 8(b)]. Thus, no transport limitation through the GaP:Si/p-Si interface was observed. However, the fill factor (FF) in this case is limited by low shunt resistance, which is obviously caused by leakage at the periphery of the $0.3 \times 0.3 \mathrm{~cm}^{2}$ small area cell. Indeed, for a larger $1 \times 1 \mathrm{~cm}^{2}$ cell with Al BSF [Fig. 8(a)], the shunt resistance is significantly higher and FF is equal to $56 \%$. The efficiency of this cell reached $5.7 \%$ with a short circuit current density (Jsc) of $21 \mathrm{~mA} / \mathrm{cm}^{2}$ which is approximately half of the maximum Jsc value that could be obtained for Si solar cells. ${ }^{1}$

The losses of Jsc should be analyzed using quantum efficiency and reflection measurements, which are presented in Fig. 9. The external quantum efficiency of GaP:Si/p-Si structures
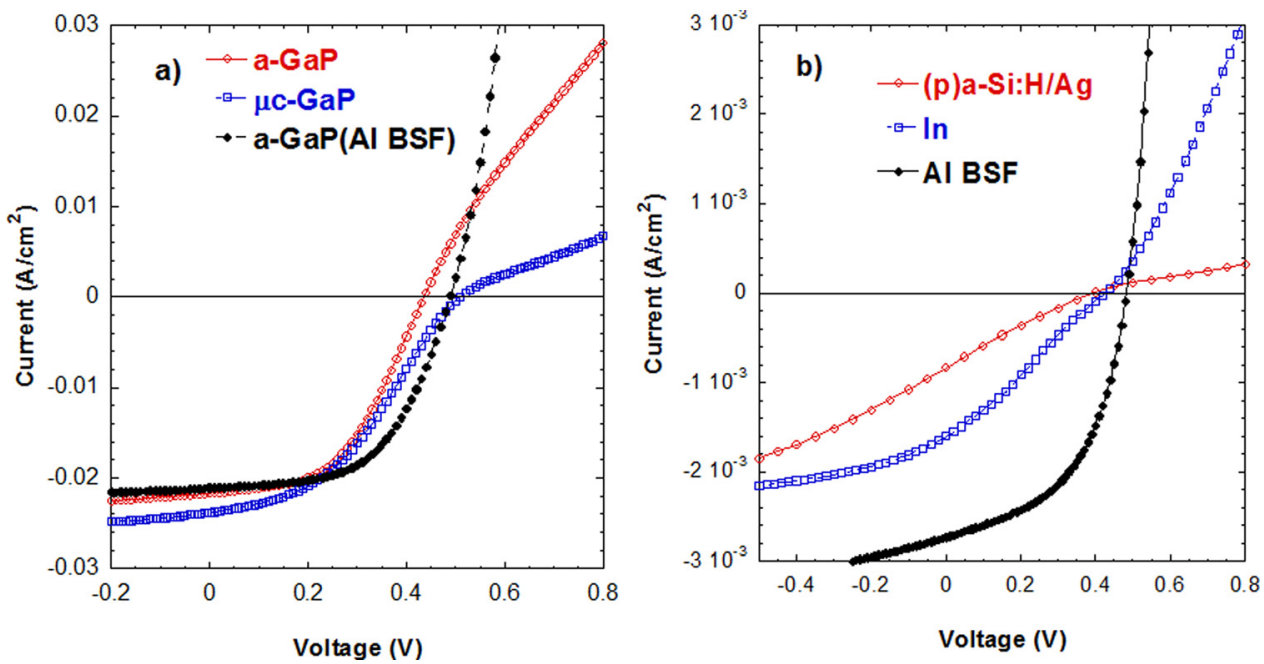

FIG. 8. I-V curves under AM1.5G for GaP:Si/p-Si $1 \times 1 \mathrm{~cm}^{2}$ cells with bottom (p)a-Si:H/Ag and Al BSF contact (a) and a$\mathrm{GaP}: \mathrm{Si} / \mathrm{p}-\mathrm{Si} 0.3 \times 0.3 \mathrm{~cm}^{2}$ cells with bottom (p) a-Si:H/Ag, In, and Al BSF contact (b). 

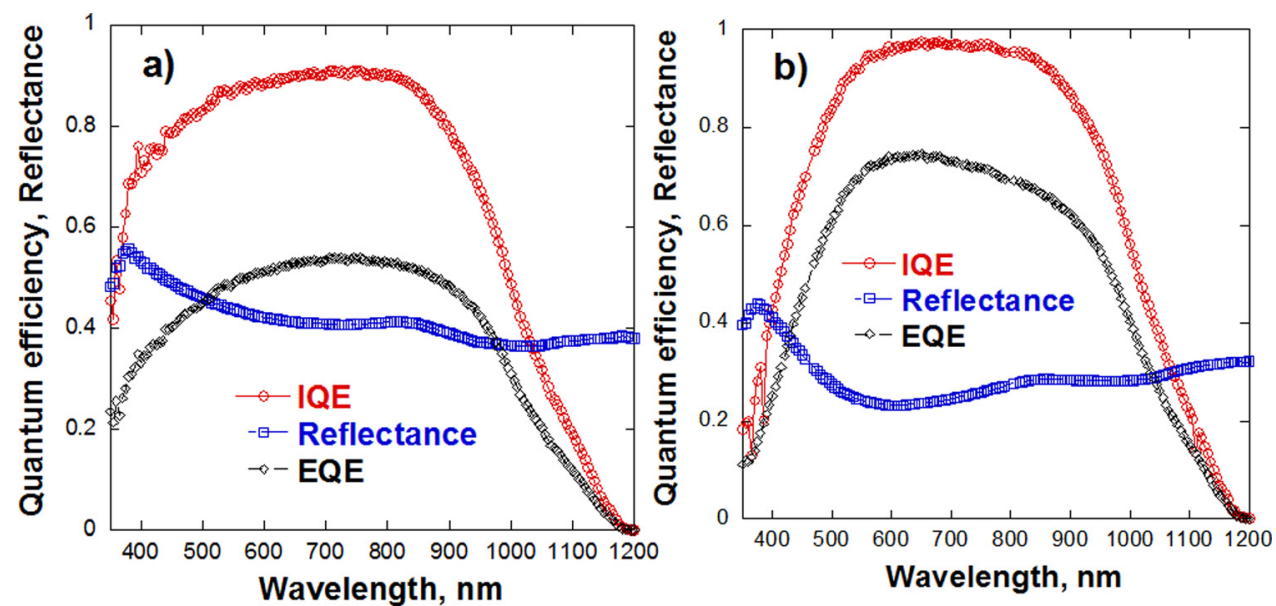

FIG. 9. External quantum efficiency (EQE), internal quantum efficiency (IQE), and reflection spectra of a-GaP:Si/p-Si (a) and $\mu \mathrm{c}-\mathrm{GaP}: \mathrm{Si} / \mathrm{p}-\mathrm{Si}$ (b) heterojunctions.

is mostly limited by significant reflection from the GaP surface (Fig. 9) because neither antireflection coating nor texturing were used. When reflection losses are taken into account, the internal quantum efficiency is relatively high in a wide spectral range. Thus, quantum efficiency is not limited by recombination losses at the $\mathrm{GaP} / \mathrm{Si}$ interface. In contrast, the decrease in internal quantum efficiency in the long wavelength region $(900-1100 \mathrm{~nm})$ demonstrates significant recombination losses in the bulk of $\mathrm{Si}$ due to the low charge carrier lifetime $(10 \mu \mathrm{s})$ of the used wafers, which also explains relatively low Voc values.

\section{CONCLUSION}

In conclusion, the growth of $\mathrm{Si}$ doped amorphous and microcrystalline GaP films by PEALD on p-type Si substrates leads to the formation of an n-type layer with a high sheet electron density $\left(>7 \times 10^{13} \mathrm{~cm}^{-2}\right)$ and an electron mobility of $13-25 \mathrm{~cm}^{2} \mathrm{~V}^{-1} \mathrm{~s}^{-1}$. This high electron concentration indicates a strong band bending in $\mathrm{p}-\mathrm{Si}$ at the $\mathrm{GaP} / \mathrm{Si}$ interface, which is relevant for photovoltaic devices. Thus, Si doped GaP films deposited by PE-ALD are promising candidates for wide bandgap emitters for Si-based heterojunction solar cells.

\section{ACKNOWLEDGMENTS}

This work was supported by the Russian Scientific Foundation under Grant No. 17-19-01482 and by PHC Kolmogorov Program (35522TL). The authors thank Patrick Chapon from HORIBA Scientific for the GDOES measurements.

${ }^{1}$ K. Yoshikawa, H. Kawasaki, W. Yoshida, T. Irie, K. Konishi, K. Nakano, T. Uto, D. Adachi, M. Kanematsu, H. Uzu, and K. Yamamoto, Nat. Energy 2, 17032 (2017).

${ }^{2}$ W. C. Cooley and R. J. Janda, Handbook of Space-Radiation Effects on Solar-Cell Power Systems (NASA, Washington, DC, 1963).

${ }^{3}$ H. Wagner, T. Ohrdes, A. Dastgheib-Shirazi, B. Puthen-Veettil, D. König, and P. P. Altermatt, J. Appl. Phys. 115, 044508 (2014).

${ }^{4}$ I. Sakata and H. Kawanami, Appl. Phys. Express 1, 091201 (2008).

${ }^{5}$ K. S. Zelentsov and A. S. Gudovskikh, J. Phys.: Conf. Ser. 741, 012096 (2016).

${ }^{6}$ R. Varache, M. Darnon, M. Descazeaux, M. Martin, T. Baron, and D. Muñoz, Energy Procedia 77, 493 (2015).

${ }^{7}$ A. S. Gudovskikh, K. S. Zelentsov, A. I. Baranov, D. A. Kudryashov, I. A. Morozov, E. V. Nikitina, and J.-P. Kleider, Energy Procedia 102, 56 (2016).

${ }^{8}$ M. Feifel, T. Rachow, J. Benick, J. Ohlmann, S. Janz, M. Hermle, F. Dimroth, and D. Lackner, IEEE J. Photovoltaics 6 , 384 (2016).

${ }^{9}$ X.-L. Wang, A. Wakahara, and A. Sasaki, J. Cryst. Growth 158, 49 (1996).

${ }^{10}$ P. Belenguer, M. Ganciu, P. Guillot, and T. Nelis, Spectrochim. Acta, Part B 64, 623 (2009).

${ }^{11}$ M. Wihl, M. Cardona, and J. Tauc, J. Non-Cryst. Solids 8-10, 172 (1972).

${ }^{12}$ S. Hayashi, Solid State Commun. 56, 375 (1985).

${ }^{13}$ J. P. Kleider, A. S. Gudovskikh, and P. Rocai Cabarrocas, Appl. Phys. Lett. 92, 162101 (2008). 
${ }^{14}$ R. Varache, C. Leendertz, M. E. Gueunier-Farret, J. Haschke, D. Muñoz, and L. Korte, Sol. Energy Mater. Sol. Cells 141, 14 (2015).

15“Gallium phosphide (GaP), electron concentration and mobility," in Group IV Elements, IV-IV and III-V Compounds. Part b - Electronic, Transport, Optical and Other Properties, Landolt-Börnstein - Group III Condensed Matter, Numerical Data and Functional Relationships in Science and Technology, edited by O. Madelung, U. Rössler, and M. Schulz (Springer, Berlin, Heidelberg, 2002), Vol. 41A1b.

${ }^{16}$ B. El-Kareh, Silicon Devices and Process Integration: Deep Submicron and Nano-Scale (Springer Science \& Business Media, 2009).

${ }^{17}$ J. P. Colinge et al., IEEE Electron Device Lett. 27, 172 (2006).

${ }^{18}$ S. M. Thomas, T. E. Whall, E. H. C. Parker, D. R. Leadley, R. J. P. Lander, G. Vellianitis, and J. R. Watling, Solid-State Electron. 53, 1252 (2009).

${ }^{19}$ S. H. Demtsu and J. R. Sites, Thin Solid Films 510, 320 (2006).

${ }^{20}$ A. S. Gudovskikh, N. A. Kaluzhniy, V. M. Lantratov, S. A. Mintairov, M. Z. Shvarts, and V. M. Andreev, Thin Solid Films 516, 6739 (2008).

${ }^{21}$ W. Tress and O. Inganäs, Sol. Energy Mater. Sol. Cells 117, 599 (2013).

${ }^{22}$ B. Vermang, F. Rostvall, V. Fjällström, and M. Edoff, Phys. Status Solidi RRL 8, 908 (2014).

${ }^{23}$ F. Anwar, S. Afrin, S. Satter, R. Mahbub, and S. Ullah, Int. J. Renewable Energy Res. 7, 885 (2017), available at: http:// www.ijrer.org/ijrer/index.php/ijrer/article/view/5688. 